\title{
UML İLE SANAL KAMPÜS MODELLEMESİ
}

\author{
1Sait Ali UYMAZ, ${ }^{2}$ Şirzat KAHRAMANLI \\ ${ }^{1}$ Selçuk Üniversitesi, Bilgi İşlem Daire Başkanlığı, KONYA \\ ${ }^{2}$ Mevlana Üniversitesi, Ĕ̆itim Fakültesi, Bilgisayar ve Öğretim Teknolojileri Bölümü, KONYA \\ ${ }^{1}$ aliuymaz@selcuk.edu.tr, ${ }^{2}$ skahramanli@mevlana.edu.tr
}

(Geliş/Received: 07.01.2016; Kabul/Accepted in Revised Form: 25.02.2016)

ÖZ: Bu çalışmada animasyonlar, görüntülü konferanslar, mobil teknolojiler ve artırılmış gerçeklik ile desteklenen öğrenci odaklı web tabanlı bir uzaktan eğitim sistemi için birleşik modelleme dili (Unified Modeling Language - UML) ile sanal kampüs modellenmesi gerçekleştirilmiştir. Sanal Kampüs modeli 4+1 bakışı içermektedir ve yazılım sürecinin aşamaları farklı UML diyagramları ile modellenmiştir. Bu modelde ilk olarak sistem aktörleri belirlenmiş ve durum diyagramları ile aktörler ve rolleri gösterilmiştir. Daha sonra durum senaryoları ve sınıf diyagramları gösterilmiştir. Ayrıca sistemi etkileyen olaylar ve etkinlikler etkinlik diyagramı ile gösterilmiştir. Son olarak sistemin alt modülleri ve fiziksel cihazları bileşen ve yaygınlaştırma diyagramları ile gösterilmiştir. Analiz ve tasarım aşamasında iyi bir modelleme yazılım sürecinde doğabilecek problemleri önler. Teknolojik yenilikler ile desteklenmiş web tabanlı bir uzaktan eğitim sistemi maliyet avantajları ile birleştiğinde ideal bir eğitim modeli olmaktadır.

Anahtar Kelimeler: İnternet Tabanlı Uzaktan Ĕ̆itim, Sanal Kampüs, Uml.

\section{Virtual Campus Modeling with UML}

\begin{abstract}
In this study, virtual campus model for student centered and web-based distance education system is carried out using unified modeling language (UML) supported by animations, video conferencing, mobile technologies and augmented reality. The model contains $4+1$ views. The phases of the software process of the model are modeled with the different UML diagrams. In this model, firstly, actors of the model are described and actors and their roles are demonstrated by state diagrams. Then, use case diagrams and class diagrams are shown. In addition, events and the sequence of activities are displayed by activity diagrams. Finally, hardware components and nodes are depicted by deployment diagrams. Making a good modeling during the design and analysis phase, avoids problems that may arise in the software process. Web-based system supported by technological innovations is an ideal educational model when combined with the cost advantages of distance education.
\end{abstract}

Key Words: Uml, Web-Based Distance Learning, Virtual Campus.

\section{GİRIŞ (INTRODUCTION)}

Eğitimde yeni teknolojilerin geliştirilmesi ve uygulanması çok önemlidir. Internet kullanımı ile uzaktan eğitim, geniş multimedya bilgilerinin sınırsız transferine ve eğitimin yer ve zamandan bağımsız 
hale gelmesine imkân verir. Öğrencilerin geri beslemesi uzaktan eğitimin kalitesini arttırabilir. Diyalog temelli uzaktan eğitim sistemi öğrencilerin bilgisinin değerlendirilmesine olanak sağlar. Uzaktan eğitim sistemi, öğrencilerin geri bildirimlerinin analizlerine, eğitim verilecek bölgenin yapısının ve yeni öğretim içeriklerinin üretilmesinin araştırılmasına dayandırılır. Bu durum öğretimin ilerlemesini ve bilgi kalitesinin gelişimini sağlar. Bir uzaktan eğitim sistemi bütünleşik veri tabanı ve www teknolojileri yoluyla uygulanır (Kovacic ve Skocir 2003).

1728 yllında Boston gazetesinin mektup ile stenografi dersleri vermesiyle başlayan ve teknolojinin gelişmesiyle birlikte radyo, televizyon ve videolar ile yaygınlaşan uzaktan eğitim, bilgisayar ve internet teknolojilerinin entegresi ile birlikte bireyler arasında çift yönlü iletişim imkânı sağlamıştır (Uzunboylu, 2008). Bilgisayar ve internet teknolojilerinin hızlı bir şekilde gelişmesi eğitimde teknoloji destekli yeni yaklaşımların ortaya çıkmasını sağlamıştır (Yıldırım ve diğ., 2004).

Ülkemizde ise uzaktan eğitim 1950'li yıllarda eğitici filmler ile başlamış ve teknolojik kaynakların kullanımı ile giderek yaygınlaşmıştır. Zaman içerisinde mektup ile öğretim, açık öğretim, televizyon ve son olarak da internet teknolojileri uzaktan eğitimde yaygınlaşmaya başlamıştır (Uymaz, 2007).

İnternet tabanlı uzaktan eğitim ile birlikte gelişen öğrenci merkezli öğrenme ortamları öğrencilerin ilgi ve motivasyonlarını yükseltebilmektedir (Altunçekiç ve Aksu, 2011). İnternet tabanlı uzaktan öğretimin en önemli özelliği, öğrencilerin bireysel özelliklerine göre farklı öğrenme etkinlikleri sunması ve ilaveten zaman ve mekân sınırlaması olmaksızın bilgiye erişim olanağı sağlamasıdır (Şahan, 2005). Yorgancı (2015) çalışmasında internet tabanlı uzaktan eğitimin zengin içerik, esneklik ve zaman tasarrufu açısından öğrencilerin başarısına etki eden bir yöntem olduğunu önermektedir. Barış ve Çankaya (2016) internet tabanlı uzak eğitim veren öğretim elemanlarının görüşlerini alarak yaptıkları çalışmada öğrencilerin sosyal hayattan uzaklaşması, iletişimin azalması ve teknolojik aksaklıklar gibi dezavantajlarının yanı sıra internet tabanlı uzaktan eğitim sisteminin zenginleştirilmiş öğrenme ortamı, fırsat eşitliği sağlaması ve zaman ve mekândan bağımsızlığı ile eğitimin kalitesini arttırdığı görüşü savunulmaktadır.

İnternet tabanlı uzaktan eğitimle birlikte yazılımcılar bu sürecin bir parçası olmuş ve eğitimin internet üzerinden daha iyi nasıl verilebilir noktasında çalışmalara başlamışlardır. İnternet tabanlı uzaktan eğitimi sadece ders materyallerinin internette yayımlama olarak değil animasyonlar, öğretici ve öğrencileri görüntülü konferanslar ile buluşturma, soru cevaplar, bölüm sonu eğitici testler, bilgiye hızlı ulaşma teknikleri ve öğrenciye uygun içerikler ile destekleme gibi daha etkin yöntemler gelişmektedir. $\mathrm{Bu}$ yöntemler yazılım geliştirme sürecini etkilemiştir ve web tabanlı uzaktan eğitim sisteminin kodlanmasından önce sağlıklı bir analiz ve modelleme yapılmasını zorunlu kılmıştır. Bu nedenle UML (Birlesik modelleme dili) programlama dilinden bağımsız olması ve birçok şematik gösterimi ile iyi bir analiz ve modelleme aracı olmuştur (Uymaz, 2007). Bu çalışmada internet tabanlı uzaktan eğitimin Uml diyagramları ile modellenmesini önerilmektedir.

\section{UZAKTAN EĞİTIM (DISTANCE LEARNING)}

Uzaktan eğitim, geleneksel eğitimin sağlanamadığı durumlarda, eğitim hizmetini sağlayan kurum ve öğreticiler ile eğitim hizmetini alan öğrenciler arasında etkileşim ve iletişimi sağlayacak yöntemlerin tek bir merkezden sağlandığı bir eğitim sistemidir (Alkan ve diğ., 1995). Uzaktan eğitimin amacı, geniş bir öğrenen kitlesine ulaşmak, derslere devam edemeyen özürlü öğrencilere ulaşmak, iş hayatı nedeniyle zaman sıkıntısı çeken insanlara ulaşmak, öğrencilerin kaynaklara erişim ve araştırmacı özelliklerini arttırmak, her öğrenciye özel kişisel eğitim imkânı vermek, monolog ortamlara hapis olmamak ve farklı kültürlerden farklı konulara hâkim öğrencilerle tanışmaktır. 


\section{İnternet Tabanlı Uzaktan Eğitim (Web-Based Distance Learning)}

Uzaktan eğitimdeki önemi sürekli olarak artan internet tabanlı eğitim, yükseköğretimde çok önemli bir yer edinmiştir. İnternet tabanlı uzaktan eğitim kullanıcılara web aracılı̆̆ıyla etkileşimli teknolojik araçlar ve yazılımlar vasıtasıyla hizmet veren öğretimsel bir platformdur (Yücel, 2006).

İnternet tabanlı uzaktan eğitimin sağladığı avantajlardan en önemlisi eşzamanlı ve eşzamansız eğitime olanak sağlayan bir sanal kampüs yaratılabilmesidir. Sanal kampüs ile uzaktan eğitim sistemine dâhil olan öğrenciler eşzamanlı olarak çevrimiçi derslere ve sınavlara katılabildikleri gibi, istedikleri zaman sistemin sağladığı kaynaklara da ulaşabilmektedirler. Öğrencilere sağlanan bu esneklik ve örgün öğretime göre maliyetinin daha düşük olması uzaktan eğitim sisteminin ideal bir model olmasını sağlamaktadır (Carswell ve Venkatesh, 2002).

İnternet tabanlı uzaktan eğitim sistemlerini internet üzerinde bulunan basit eğitim sayfalarından ayıran temel özellikleri mevcuttur. Eğitim sisteminin hizmet vereceği kitle ve uzaktan eğitimin amacı sistemin temel özelliklerinde değişikliğe neden olsa da genel hatlarıyla aşağıdaki fonksiyonları barındırması gerekmektedir (Aslantürk, 2002; Uymaz, 2007).

- Sistemin temel kullanıcıların tanımlanması ve yönetilmesi

- Ders içeriklerinin (metin, sunu, animasyon, 3D içerik vb.) hazırlanması ve yönetilmesi

- Öğrenciye özel programların açılması ve yönetilmesi

- Verilen teorik bilgilerin uygulamalarının yapılabilmesi için ödev ve proje verilmesi

- Dönem ve yılsonu sınavları ile dönem içi testlerin hazırlanması ve uygulanması

- Öğrenci davranışlarının izlenmesi ve incelenmesi

- Öğrencilerin katıldıkları programlarda başarı durumlarının değerlendirilmesi

- Öğrenci ve öğretici arasında etkileşimli iletişim ortamlarının oluşturulması ve yönetilmesi

İnternet tabanlı uzaktan eğitim sistemlerinde teknolojik gelişmeler ile beraber eğitim içerikleri de paralel olarak gelişmekte ve değişmektedir. Mobil teknolojiler ve bulut sistemlerin gelişimi ile veri saklama ve işleme sorunları büyük ölçüde aşılmaktadır. Web teknolojilerinin gelişimi etkileşimli içeriklerin daha kolay hazırlanmasını sağlamaktadır. HTML 5 ile multimedya içeriklerin Flash gibi ara çözümler kullanma zorunluluğunu azaltmaktadır. Mobil teknolojilerin gelişimi ile uzaktan eğitimde yeni araçların kullanımı da artmaktadır. Bu teknolojilerden Apple firmasının Siri yazılımı sesli komutlar ile mobil cihazların yönetilmesini sağlamaktadır. Google Glass ise sesli komutlar ve göz hareketleri ile çalışabilen bir araçtır. Ayrıca yeni teknolojilerden arttırılmış gerçeklik kullanıcıya gps, barkod vb. verilere bağlı olarak hazırlanan metin, video ve 3 boyutlu model gibi içerikler sunmaya yarayan bir teknolojidir (Torkul ve diğ., 2013).

\section{Uml (Unified Modelling Language)}

UML Türkçeye "Birleşik Modelleme Dili" olarak çevrilmektedir. UML bir bilgisayar yazılımını kodlamaya başlamadan önce sistemin modellenebileceği ve sistem adımlarının, kullanılacak yöntemlerin, kullanıcıların ve kullanıcılar arası etkileşimlerin açıklanabildiği yöntemlerin bir araya toplanmış halidir. Günümüz yazılım teknolojisi ile geliştirilen programların karmaşıklığı ve zorluğu artmaktadır. Geliştirilen yazılımların farklı teknolojik platformlarda kullanılmaya başlanması ile yazılım süreçlerini zorlaştırmaktadır. Geliştirilen yazılımların karmaşıklığı ve zorluğu kod organizasyonu yapmayı da zorlaştırmaktadır. Bu nedenle standart bir modelleme ve analiz diline ihtiyaç duyulmaktadır. Analiz ve tasarım aşamasında iyi bir modelleme yazılım aşamasında doğabilecek birçok problemin ortaya çıkmasına engel olur (Uymaz, 2007). UML'nin sunduğu diyagramlar aşağıdaki gibidir.

- Sinif diyagramları

- Nesne diyagramları

- Durum diyagramları 
- Sıra etkileşim diyagramları

- Etkinlik diyagramları

- Kullanim durum diyagramları

- Bileşen diyagramları

- Yaygınlaştırma diyagramları

- İletişim diyagramları

- Zamanlama diyagramları

- Etkileşim tanıtma diyagramları

- Karma yap 1

- Paket diyagramları

\section{SANAL KAMPÜS MODELLEMESİ (VIRTUAL CAMPUS MODELING)}

Sanal kampüs sistemi oluşturulurken tek boyutta analiz ve modelleme yeterli gelmemektedir. Bu nedenle, 4+1 bakış ile yazılım geliştirme sürecinin farklı aşamalarını farklı UML diyagramları ile modellemek sistemin yaşam sürecini ortaya koymak için gereklidir.

\section{Asama: Kullanııı Bakışı (User View)}

$\mathrm{Bu}$ aşamada ilk olarak uzaktan eğitim sisteminin temel aktörleri ve rolleri belirlenmiştir. İş akışlarında olayları başlatan aktörlerdir. Aktörler yazılımın bir bileşeni olabildiği gibi sistemin dışında olan ve sistem ile etkileşimde bulunan başka bir sistem veya yazılımı kullanan bir birey de olabilir. Modellenen sistemin aktörleri, öğrenci, öğretmen, sistem yöneticisi ve alt sistemdir. Sistemin tüm aktörlerinin bilgileri tanımlanmış ve Çizelge 1'de öğrenci aktör bilgileri verilmiştir. Şekil 1'de sanal kampüste bulunan aktörler ve onların rolleri genel olarak tek bir kullanım durum diyagramında gösterilmektedir. 
Çizelge 1. Öğrenci aktörü bilgileri

Table 1. Information of Student Actor

\begin{tabular}{|c|c|}
\hline Ad1 & [SANAL KAMPUS ÖGRENCISİ] \\
\hline $\begin{array}{l}\text { Aktör } \\
\text { Tanımlayıcısı }\end{array}$ & ÖĞRENCİ \\
\hline Rol (ler) & 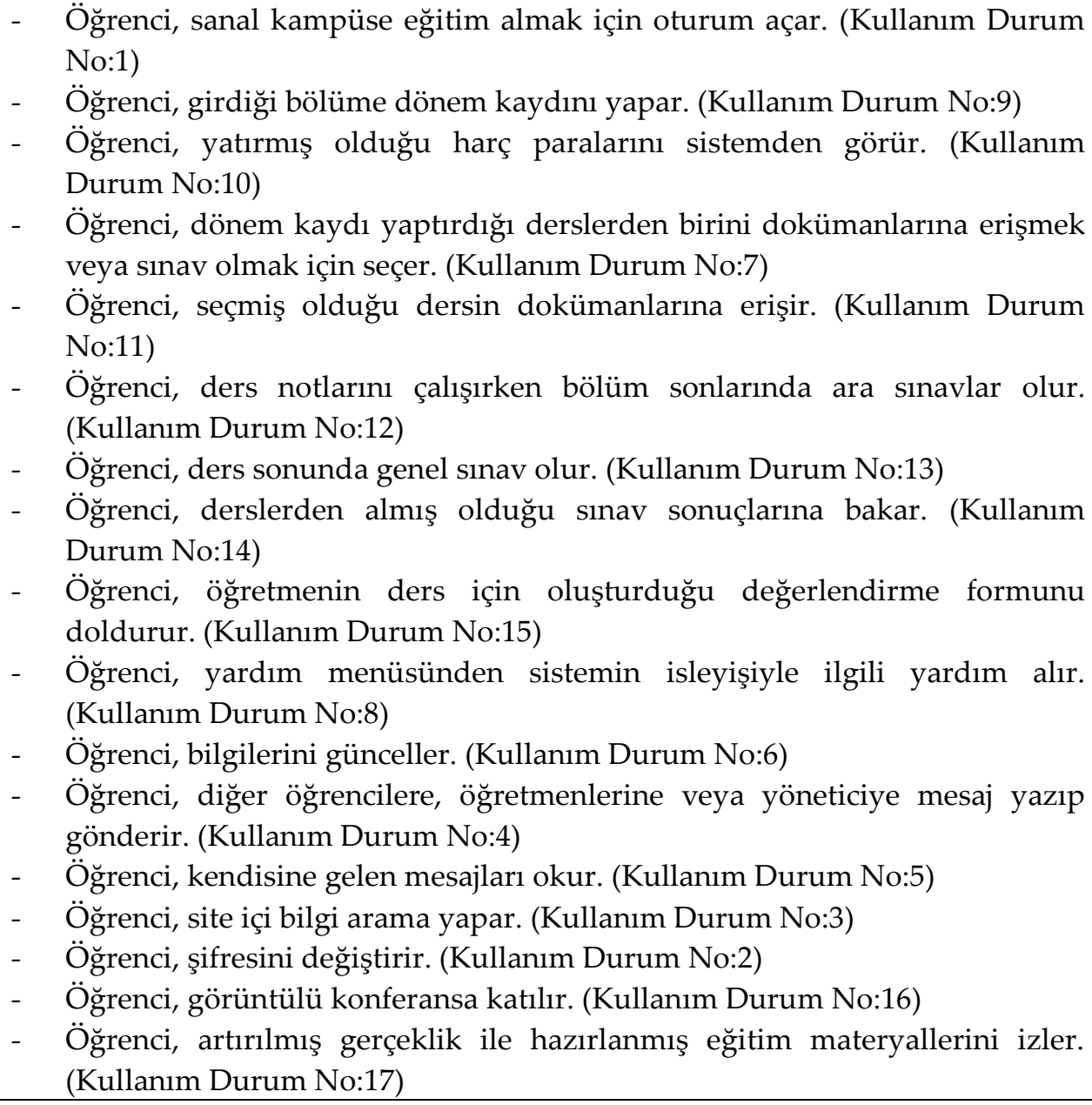 \\
\hline İş Bilgisi & Düşük, iş akışı teknik terimler ve sistemin yapısı hakkında fazla bilgisi yoktur. \\
\hline Teknik Bilgisi & $\begin{array}{l}\text { Orta, Bilgisayar bilgisi vardır. Sanal Kampus üzerinde bulınan özellikleri } \\
\text { kullanabilir fakat sistemin isleyişi hakkında yardım sağlanmalıdır. }\end{array}$ \\
\hline $\begin{array}{l}\text { Diğer } \\
\text { Özellikler }\end{array}$ & $\begin{array}{l}\text { Sanal Kampus öğrencisidir. Sistemde bilgileri mevcuttur. Sisteme giriş } \\
\text { yapabilir. }\end{array}$ \\
\hline Say1 & $\begin{array}{l}\text { Hedeflenen Sanal Kampüse kayıtlı öğrenci sayısı, ilk yıl için } 5 \text { bin, ikinci yıl için } \\
10 \text { bin ve bu sayının } 50 \text { bine ulaşması öngörülmektedir. }\end{array}$ \\
\hline
\end{tabular}




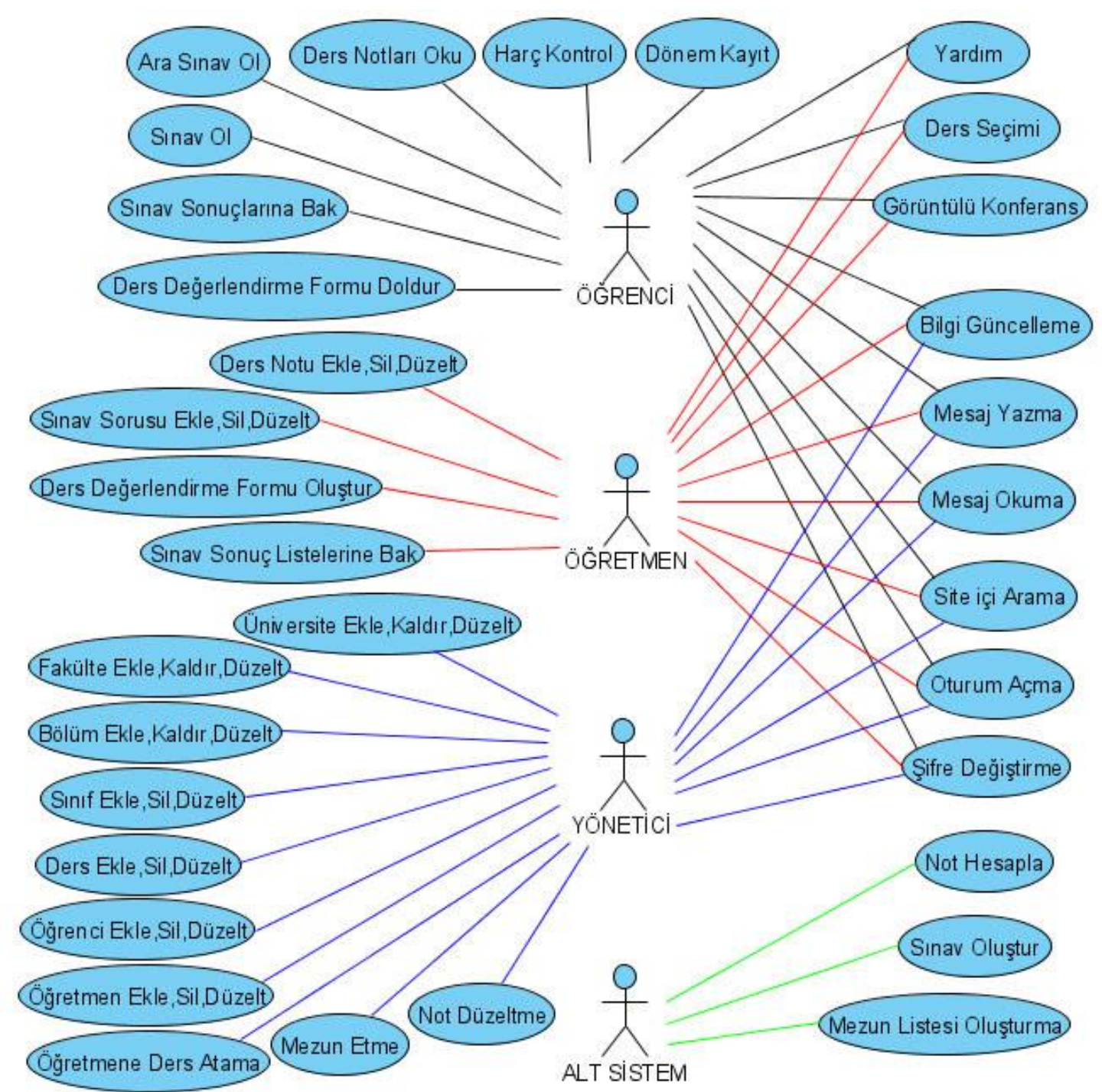

Şekil 1. Sanal Kampus Kullanım Durumu Genel Diyagramı (Uymaz, 2007)

Figure 1. Use Case Diagram of Virtual Campus

Aktörler ve kullanım durum diyagramları tanımlandıktan sonra durum senaryoları tanımlanmıştır. Kullanım durum senaryoları belirli bir şablonda ve kolay anlaşılır biçimde hazırlanmıştır. Senaryo şablonları ve kuralları hakkında ayrıntılı bilgi Uymaz (2007) çalışmasından incelenebilir. Çizelge 2'de oturum açma durum senaryosu gösterilmiştir. 
Çizelge 2. SANALKAMPUS.SN1 Oturum Açma senaryosu

Table 2. Logon Scenario

\begin{tabular}{|c|c|c|c|}
\hline \multicolumn{2}{|l|}{ Senaryo \# } & \multicolumn{2}{|l|}{1} \\
\hline \multicolumn{2}{|l|}{ Senaryo ismi } & \multicolumn{2}{|l|}{ Oturum Açma } \\
\hline \multicolumn{2}{|l|}{ Kapsam } & \multicolumn{2}{|l|}{ İş Süreci (Şeffaf-Kutu) } \\
\hline \multicolumn{2}{|l|}{ Hedef Seviye } & \multicolumn{2}{|l|}{ Detay Fonksiyonlar } \\
\hline \multicolumn{2}{|l|}{ Aktör(ler) } & \multicolumn{2}{|l|}{ Öğrenci, Öğretmen, Yönetici } \\
\hline \multicolumn{2}{|l|}{ Hedef } & \multicolumn{2}{|c|}{$\begin{array}{l}\text { Bu senaryoda kayıtl } \\
\text { hedeflenmiştir. }\end{array}$} \\
\hline \multicolumn{2}{|l|}{ Amaç } & \multicolumn{2}{|c|}{$\begin{array}{l}\text { Sistemde farklı görevleri olan birçok kullanıcı vardır. Bu kullanıcıların } \\
\text { kendi işlemlerini yapabilecek sayfalarına ulaşmaları amaçlanmıştır. } \\
\text { Sisteme giriş sadece yetki dâhilinde olmalıdır. }\end{array}$} \\
\hline \multicolumn{2}{|l|}{ Olgunluk } & \multicolumn{2}{|c|}{ Sarı } \\
\hline \multicolumn{2}{|l|}{ Sorular } & \multicolumn{2}{|c|}{$\begin{array}{l}\text { 1- Kullanıcı şifrelerinin belli bir uzunlukta ve formatta olması gerekli } \\
\text { midir? } \\
\text { Güvenliği arttırmak için gerekli olabilir. }\end{array}$} \\
\hline \multicolumn{2}{|l|}{ Ön durumlar } & \multicolumn{2}{|c|}{$\begin{array}{l}\text { Bir Öğrencinin sisteme giriş yapabilmesi için harcını yatırmış olması } \\
\text { gerekir. } \\
\text { Bir Öğretmenin sisteme giriş yapabilmesi için üzerine ders } \\
\text { tanımlanmış olması gerekir. }\end{array}$} \\
\hline \multicolumn{2}{|c|}{ Başarılı bitiş durumları } & \multicolumn{2}{|c|}{ Sistemde oturum açma gerçekleşir. } \\
\hline \multicolumn{2}{|c|}{ Minimum bitiş durumları } & \multicolumn{2}{|c|}{ Sisteme giriş denemesi log dosyalarına kayıt edilir. } \\
\hline \multicolumn{4}{|c|}{ Ana İş Akışı } \\
\hline \multicolumn{4}{|c|}{$\begin{array}{l}\text { 2. Sistem kullanıcı adı ve şifreyi veritabanından kontrol eder ve doğrulanırsa aktörün } \\
\text { yapabileceği işlemler menüsüne geçer. } \\
\text { 3. Kullanıcıya özel oturum açar. }\end{array}$} \\
\hline \multicolumn{4}{|c|}{ Alternatif İş Akışı } \\
\hline \multicolumn{4}{|c|}{$\begin{array}{l}\text { 2A. Koşul: Kullanıcı hatalı kullanıcı adı veya şifre girer. } \\
\text { A2. Adım } 1 \text { Sistem Kullanıcı adı ve/veya şifrenin hatalı } \\
\text { ve şifreyi yeniden ister. } \\
\text { A2. Adım } 2 \text { Kullanıcı bilgileri yeniden girer. } \\
\text { A2. Adım } 3 \text { Bilgiler doğru ise ana akışa dönülür. } \\
\text { A2. Adım } 4 \text { Tekrar yanlış girilirse yeniden sorulur. } \\
\text { A2. Adım } 5 \text { Beş kez yanlış girilirse akış sona erdirilir. }\end{array}$} \\
\hline \multicolumn{4}{|c|}{ Belge Tarihçesi } \\
\hline Tarih & Sürüm & Açıklama & İsim \\
\hline 01/May1s/2007 & 0,1 & ìlk sürüm oluşturuldu. & Sait Ali Uymaz \\
\hline 07/Mayıs/2007 & 0,2 & Alternatif is akısına 5 . Madde eklendi & Sait Ali Uymaz \\
\hline
\end{tabular}




\section{Aşama: Yapısal Bakış (Structural View)}

Kullanım durum senaryoları oluşturduktan sonra bu senaryolar üzerinde ki sınıfları ortaya koymak gerekmektedir. Sınıf diyagramlarını çizerken öncelikle sınıfların özelliklerini, işlevlerini ve diğer sınıflar ile ilişkilerini belirtmek gerekir. Sınıf diyagramları nesneye yönelik modellemenin yapı taşıdır ve sistemin genel görünümü ile ilgili bilgi verir. Şekil 2 ile Sanal Kampus modeli için seçilen 14 sınıfın özellikleri, işlevleri ve aralarındaki ilişkiler Uml'nin sınıf diyagramı ile modellenmiştir.

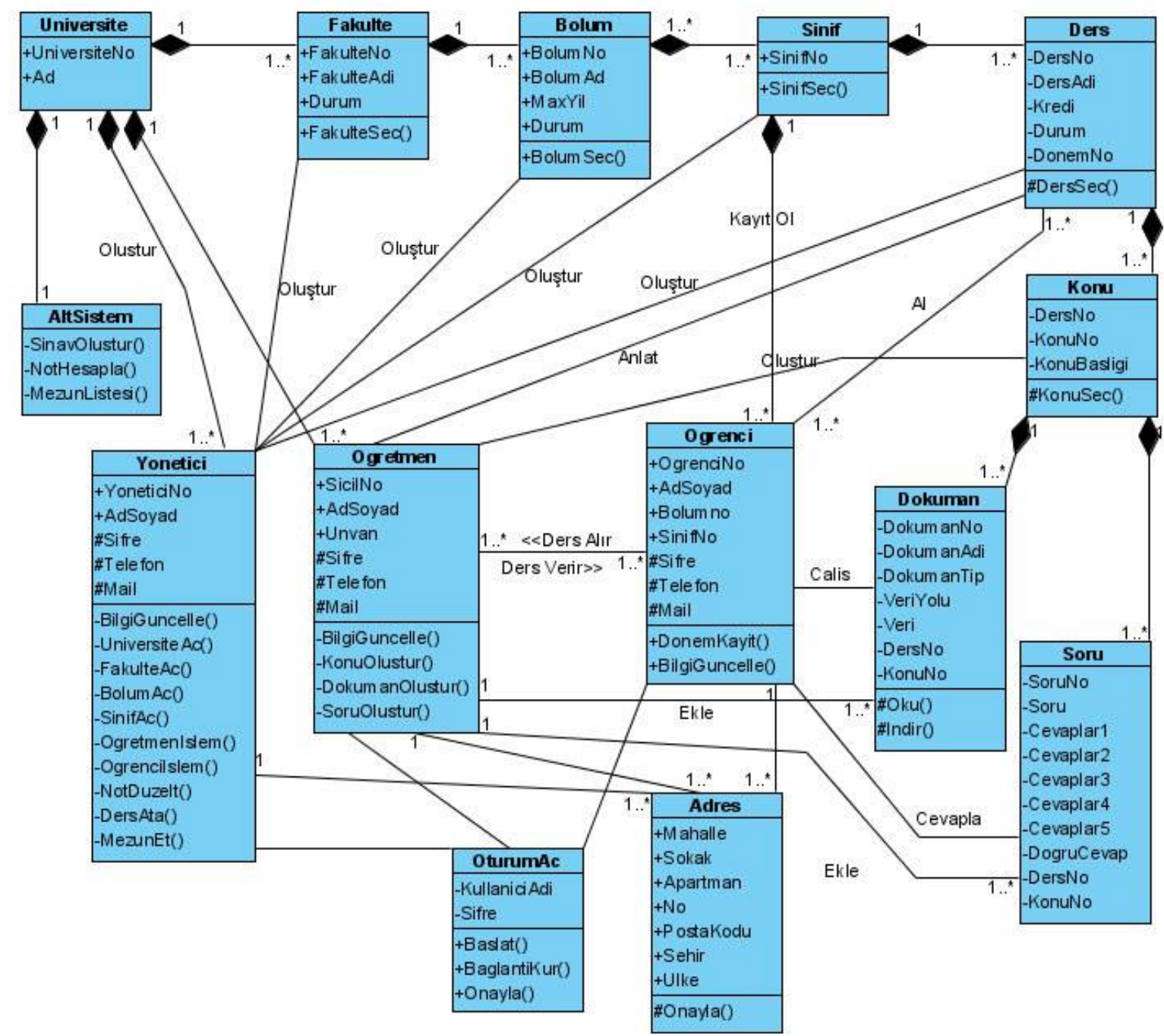

Şekil 2. Sanal Kampus Sınıf Diyagramı

Figure 2. Class Diagram of Virtual Campus

\section{Aşama: Davranış Bakışı (Behavioral View)}

İlk iki aşamada, senaryolar ve bu senaryolarda ki sınıflar, sınıflar arasındaki kavramsal ilişkiler gösterilmiştir. Davranış bölümünde nesnelerin ve sistemin durumlarını etkileyen olaylar ve etkinlikler soyut bir düzeyde incelenmektedir. Nesnelerin programın kendi akışı içerisinde gerçekte nasıl bir işbirliği yaptığı, nasıl bir etkileşimde bulunduğu modellenmiştir. Bu modelleme de Uml'nin durum, etkinlik ve ardışık sıra diyagramlarından faydalanılmıştır. Şekil 3 ile öğrencinin dönem kaydı etkinlik diyagramı ile gösterilmiştir. 


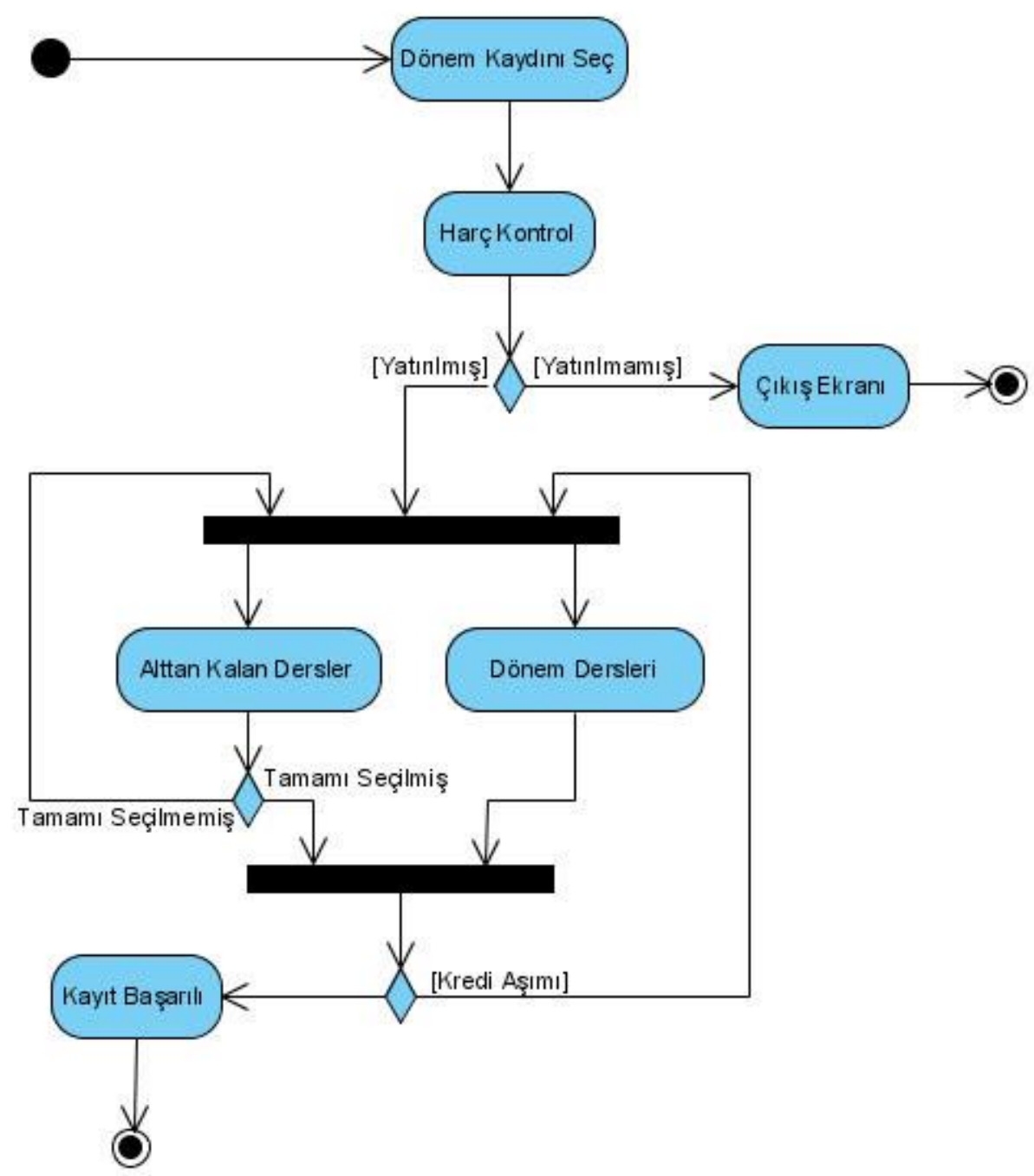

Şekil 3. Dönem Kayıt Etkinlik Diyagramı

Figure 3. Activity Diagram of Semester Registration

Ardışık sıra diyagramları ile nesnelerin birbirleri ile haberleşmesi zamana bağlı olarak ele alınmaktadır. Ardışık sıra diyagramları zaman çizelgesi üzerinde nesneleri ve nesneler arası mesajları göstermektedir. Bu diyagramlarda akış soldan sağa doğru gösterilmektedir. Bir olayı ardışık sıra diyagramları ile göstermeden önce senaryosu çıkarılmalıdır. Şekil 4 ile senaryosu çıkarılmış olan sınav uygulamasının ardışık sıra diyagramı gösterilmiştir. 


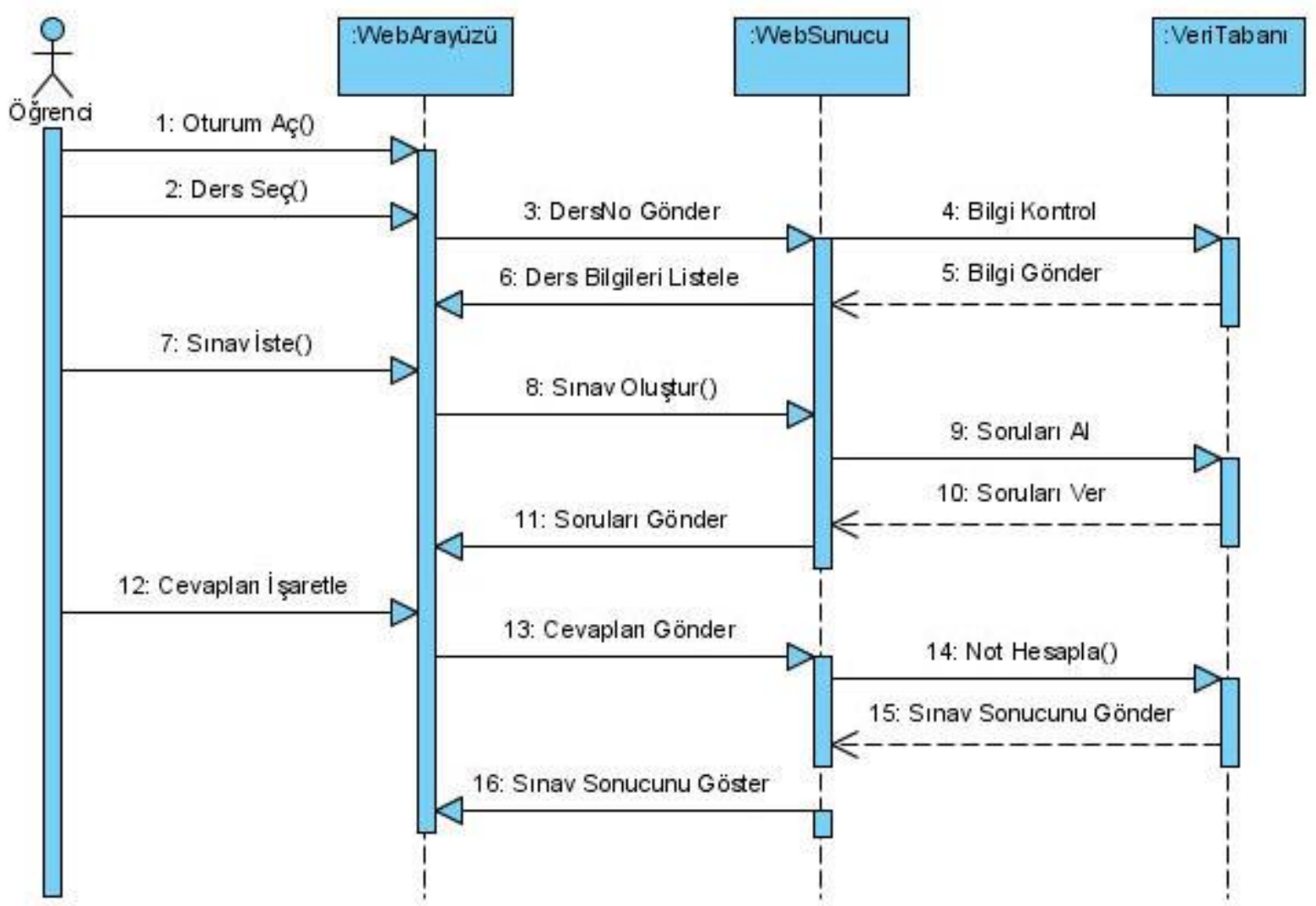

Şekil 4. Sınav Ardışık Sıra Diyagramı

Figure 4. Sequence Diagram of Quiz System

4. Aşama: Gerçekleştirme Bakışı (Implementation View)

Gerçekleştirme bakışı uzaktan eğitim sisteminin alt modüllerinin ortaya koyulduğu bölümdür. Bu modellemede kullanılan bileşenler katmanlar halindedir ve her katmanın bir arayüzü mevcuttur. Bileşenler tek başına çalışabilir, yer değiştirilebilir veya sistemden çıkarılabilir. Geliştirilen sistemin ihtiyaçları doğrultusunda yeni bileşenler sisteme kolaylıkla ilave edilebilir. Bu sayede sistem daha esnek bir yapıya kavuşmaktadır. Şekil 5 ile sanal kampüs sisteminin alt modüllerini bileşen diyagramını göstermektedir. 


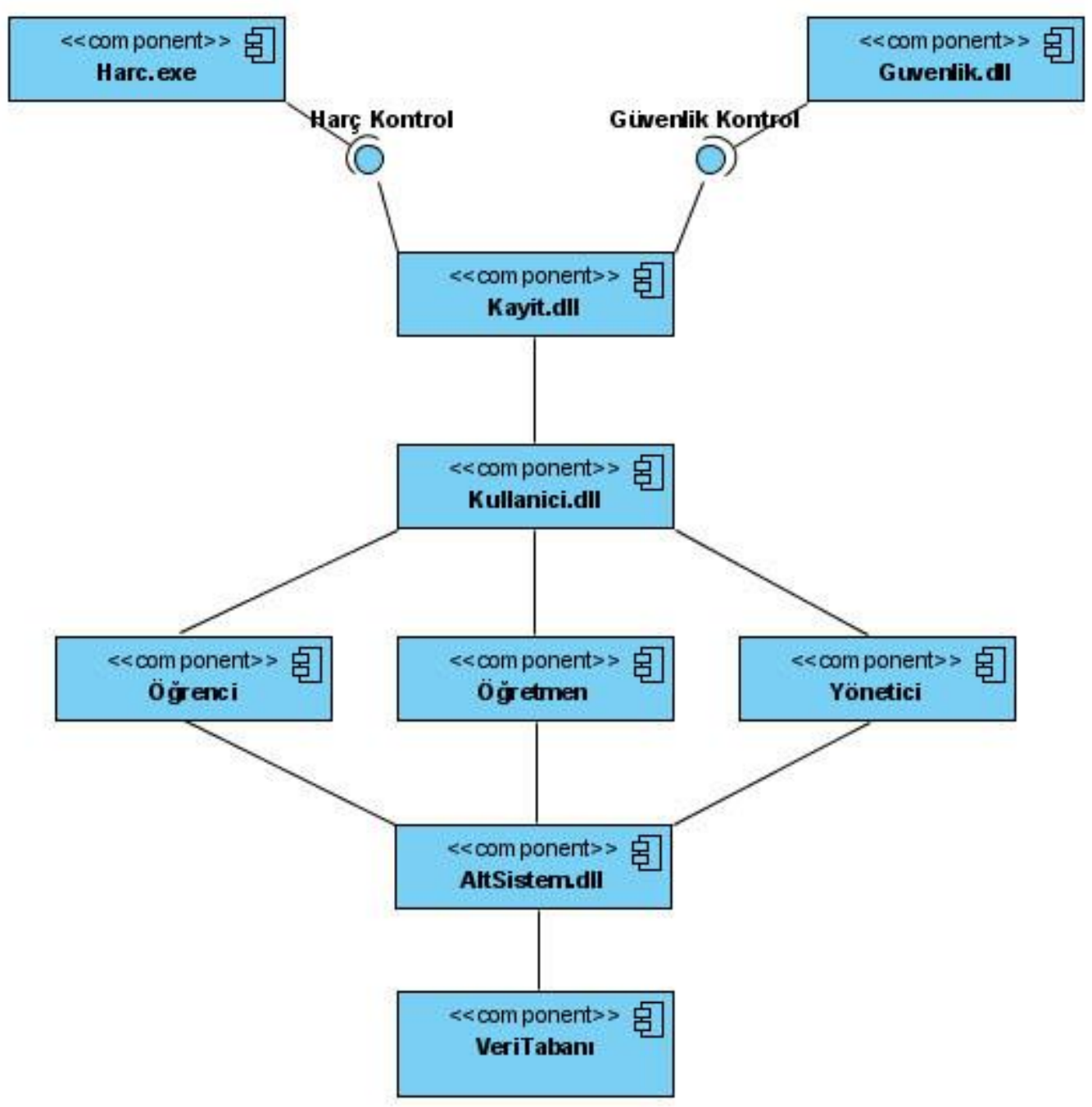

Şekil 5. Sanal Kampüs Bileşen Diyagramı

Figure 5. Component Diagram of Virtual Campus

5. Aşama: Ortam Bakışı (Environment View)

Ortam bakışı uzaktan eğitim sistemi yazılımlarının çalışacağı fiziksel mimarinin ortaya koyulduğu bakış açısıdır. Uzaktan eğitim sisteminin nasıl çalışacağını gösteren en üst düzey bakıştır. Ortam bakışı yaygınlaştırma diyagramları ile gösterilmiştir. Yaygınlaştırma diyagramında uzaktan eğitim sisteminin kurulumunda gerekli fiziksel cihazlar (kişisel bilgisayarlar, sunucular, yazıcılar ve network cihazları vb.) ve bileşen diyagramında gösterilen alt modüller birlikte kullanılmaktadır. 


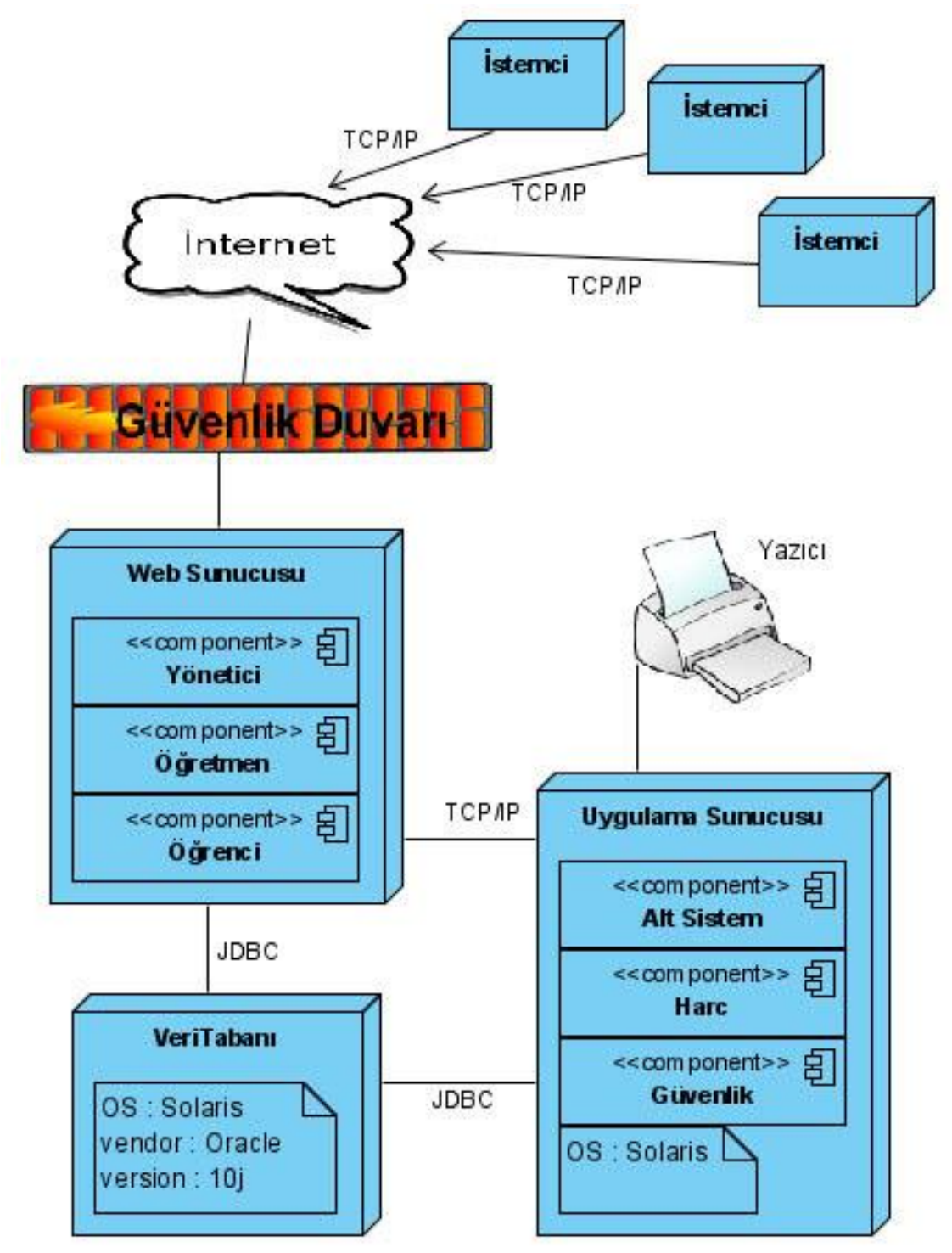

Şekil 6. Sanal Kampüs Yaygınlaştırma Diyagramı Figure 6. Deployment Diagram of Virtual Campus

\section{SONUÇ ve TARTIŞMALAR (RESULTS and DISCUSSIONS)}

Teknolojinin gelişimi, yaygınlaşması, internetin kullanım oranlarının artması, yükseköğretime olan ihtiyacın ve talebin artması, geleneksel altyapı imkanlarının yetersizliği ve yaşam boyu eğitimin rekabet için gerekli hale gelmesi uzaktan eğitim çalışmalarını arttırmış ve üniversiteleri örgün eğitime ilaveten uzaktan eğitim konusunda çalışma yapmaya veya hizmet vermeye yöneltmiştir. Sistemin iyi modellenmesi, teknolojik yeniliklerin kullanılması ve eğitimin öğrenci merkezli olarak verilmesi uzaktan eğitimdeki başarıyı etkilemektedir.

Teknolojik gelişmeler ve internetin yaygınlaşması internet tabanlı uzaktan eğitim sistemlerini yaygınlaştırmıştır. Birçok teknolojik altyapının birlikte kullanılması bu sistemlerin karmaşıklığını arttırmaktadır. Bu nedenle internet tabanlı bir uzaktan eğitim sisteminin modellenmesi büyük önem taşır. Bu çalışmada önerilen uzaktan eğitim sistemi, 4+1 bakışı ile yazılım geliştirme sürecini farklı UML diyagramları yardımı ile modellemektedir. Bu modelde sistemin temel aktör ve rolleri belirlenmiş ve kullanım durum senaryoları, bu senaryolar üzerindeki sınıfların özellikleri, işlevleri ve sınıflar arası ilişkiler ortaya konmuştur. 
Davranış bakışında sistemdeki nesnelerin program akışı içerisinde nasıl işbirliği yaptığı ve nasıl etkileşimde bulundukları modellenmiştir. Ardışık sıra diyagramları ile nesnelerin birbirleriyle etkileşimleri zamana bağlı olarak ele alınmıştır. Gerçekleştirme ve ortam bakışlarında sistemin alt modülleri ve yazılım sisteminin üzerinde çalışacağı fiziksel mimari ortaya koyulmuştur.

Yeni teknolojiler kullanılarak çağın ihtiyaçlarına uygun hazırlanmış eğitim araçları ile iyi düşünülmüş ve modellenmiş bir uzaktan eğitim sistemi öğrencilerin uzaktan eğitime yönelmelerini sağlayabilir ve eğitim maliyetlerini düşürebilir.

\section{KAYNAKLAR (REFERENCES)}

Alkan, C., Deryakulu, D. ve Şimşek, N., 1995, Eğitim Teknolojisine Giriş: Disiplin, Süreç, Ürün. Önder Matbaacılık Ltd.Şti., Ankara.

Altunçekiç, A. ve Aksu, L., 2011, Web Destekli Öğrenme Ortamlarının İnternet Kullanımına Yönelik Tutum Düzeyleri Üzerine Etkisi, Kastamonu Eğitim Dergisi, 19 (1), 239-250.

Aslantürk, O. (2002). Bir Web tabanlı uzaktan eğitim sisteminin tasarlanması ve gerçekleştirilmesi. Yayımlanmamış yüksek mühendislik tezi, Hacettepe Üniversitesi, Ankara.

Barış, M. F. ve Çankaya, P., 2016, Opinions of academic staff about distance education, International Journal of Human Sciences, 13(1), 399-413.

Carswell, A.D. ve Venkatesh, V. (2002). Learner outcomes in an asynchronous distance education environment. International Journal of Human-Computer Studies, 56(5), 475-494.

Kovacic, B. ve Skocir, Z., 2003, Development of Distance Learning System Based on Dialogue, EUROCON 2003, Ljubljana, Slovenia, 224-228.

Mishra, J. and Mohanty, A., 2011, Software Engineering, Pearson Education India, 123-125.

Şahan, H. H. (Editör: DEMİREL, Ö.), 2005, İnternet Temelli Öğretim, Eğitimde Yeni Yönelimler, Ankara: Pegem A Yayıncilık, 223-233.

Torkul, O., Cedimoğlu, İ. H. ve Cesur, M. R., 2013, Bilgi çağı öğretim modeli, Ulusal Uzaktan Eğitim ve Teknolojileri Sempozyumu, Konya, 182-186.

Uymaz, S. A., 2007, UML ile sanal kampüs modellemesi, Yüksek lisans Tezi, Selçuk Üniversitesi Fen Bilimleri Enstitüsü, Konya, 2-99.

Uzunboylu, H., 2008, Öğretim Teknolojileri ve Materyal Tasarımı, Ankara: Pegem Akademi Yayıncılık, 199-201.

Yıldırım, S., Temur, N., Kocaman, A. ve Göktaş, Y., 2004, What makes a good LMS: An analytical approach to assessment of LMSs, Ithet 2004: Proceedings of the Fifth International Conference on Information Technology Based Higher Education and Training, 125-130.

Yorgancı, S., 2015, Web tabanlı uzaktan eğitim yönteminin öğrencilerin matematik başarılarına etkileri, K. Ü. Kastamonu Eğitim Dergisi, 23 (3), 1401-1420.

Yücel, S. A., 2006, E-learning approach in teacher training, Turkish Online Journal of Distance Education-TOJDE, 7(4), 123-131. 